-Full Paper-

\title{
Resistance to 5-aza-2'-deoxycytidine in Genic Regions Compared to Non-genic Repetitive Sequences
}

\author{
Hui Wen LIM ${ }^{1}$, , Misa IWATANI ${ }^{1)}$, Naoko HATTORI ${ }^{1)}$, Satoshi TANAKA ${ }^{1)}$, Shintaro YAGI ${ }^{1)}$ and \\ Kunio SHIOTA ${ }^{1)}$ \\ ${ }^{1)}$ Laboratory of Cellular Biochemistry, Animal Resource Sciences/Veterinary Medical Sciences, The University of Tokyo, \\ Tokyo 113-8657, Japan
}

\begin{abstract}
The DNA methyltransferase (Dnmt) inhibitor and demethylating agent 5-aza-2'-deoxycytidine (5azadC) has been used to induce cellular differentiation and gene activation. It has been approved for treating several kinds of malignancies due to its ability to reactivate silenced tumor suppressor genes. Considering the potential effect of 5azadC on non-targeted genomic regions in normal cells, we investigated its effect on repetitive sequences and selected gene loci, Oct-4, Sall3, Per1, Clu, Dpep1 and Igf2r, including tissue-dependent and differentially methylated regions, by treating mouse $\mathrm{NIH} / 3 \mathrm{~T} 3$ fibroblast cells with concentrations of $5 \mathrm{azadC}$ ranging from 0.001 to $5 \mu \mathrm{M}$. Demethylation of minor satellite repeats and endogenous viruses was concentration dependent, and the demethylation was strong at 1 and $5 \mu \mathrm{M}$. In genic regions, the methylation level decreased only at $0.1 \mu \mathrm{M}$, but was minimally altered at concentrations lower or higher, regardless of the abundance of $\mathrm{CpG}$ sites. Thus, repeats are strongly demethylated, but genic regions are only demethylated at effective doses. Genes were activated by 5azadC treatment and were accompanied by a unique combination of histone modifications in genic regions, including an increased level of $\mathrm{H} 3 \mathrm{~K} 9 \mathrm{me} 3$ and a decreased level of AcH3. Increase of $\mathrm{H} 3 \mathrm{~K} 9 \mathrm{me} 3$ in genic regions was not observed in Dnmt knock out cells. We identified differential effects of $5 \mathrm{azadC}$ on repetitive sequences and genic regions and revealed the importance of choosing appropriate $5 \mathrm{azadC}$ doses to achieve targeted gene recovery.
\end{abstract}

Key words: 5-aza-2'-deoxycytidine, Decitabine, DNA methylation, Epigenetics, Histone modification

(J. Reprod. Dev. 56: 86-93, 2010)

D NA methylation is one of the epigenetic events associated with gene regulation and function. Hypermethylation of promoter regions of tumor suppressor genes causes silencing of the genes that lead to cancer [1-3]. Thus, reversing the methylation status of gene promoters to their prevalent methylation states has become a treatment option for certain cancer types. To date, there are many types of demethylating agents that have been shown to inhibit promoter methylation and reactivate silenced genes [4-6]. Some of these have been approved or are in clinical studies to be developed as cancer drugs [7].

The cytosine analog 5-aza-2'-deoxycytidine (5azadC), also known as decitabine, has been widely used as a DNA methyltransferase (Dnmt) inhibitor to reverse aberrant hypermethylation [8, 9]. It has been approved for hematological malignancies, showing favorable results with low dose treatment $[10,11]$. Known to have dual modes of action, 5azadC at low doses induces gene hypomethylation, whereas high doses of 5azadC induce cytotoxicity and cause severe side effects in patients $[12,13]$.

Nearly $40 \%$ of the mouse genome is composed of repetitive sequences including different classes of interspersed repeats, such as LINEs, SINEs, LTR elements and satellites, that are mainly found in heterochromatin regions [14]. Most repeats are densely methylated, and methylation in repeats reflects the global methyla-

Received: March 17, 2009

Accepted: October 3, 2009

Published online in J-STAGE: December 9, 2009

(C)2010 by the Society for Reproduction and Development

Correspondence: K Shiota (e-mail: ashiota@mail.ecc.u-tokyo.ac.jp) tion level $[15,16]$. Loss of methylation in repeats causes genomic instability $[17,18]$. Conversely, genes comprise only a small portion of the genome. Tissue-dependent and differentially methylated regions (T-DMRs) are unique sequences in genic regions that are methylated depending on tissue or cell types. TDMRs have been widely observed, including in undifferentiated embryonic stem cells, normal tissues and even in cloned mice [1921]. Both repetitive regions and T-DMRs serve as important markers for methylation analysis, as repeats could be used to estimate global methylation, whereas T-DMRs could serve as references for cell- or tissue-specific methylation.

Previous reports show that Dnmts exhibit functional cooperation on genomic regions [22, 23]. We reported previously that Dnmt1, Dnmt3a and Dnmt3b share targets in the same CpG islands with TDMRs, and each Dnmt has target preferences depending on the genomic regions [24]. Dnmt3a and Dnmt3b prefer T-DMRs of genic regions, whereas Dnmt1 prefers repetitive sequences.

The demethylating effect of 5azadC is exerted by binding to Dnmts [4]. Since Dnmts have multiple targets, there is the potential of having a genome-wide demethylating effect when using 5azadC. Demethylation of non-targeted genomic regions might occur, not only in cancer cells but also in normal cells. In addition, there are diverse interactions between DNA methylation and histone modifications in euchromatic and heterochromatic regions $[25,26]$. The epigenetic status of T-DMRs is regulated by the interplay between DNA methyltransferases, histone modification enzymes, nuclear proteins and other epigenetic factors that cooperate to form cell- and tissue-specific DNA methylation profiles [27, 
28]. It may be possible to induce hypomethylation-independent activation of gene expression and downstream responses. To know whether 5azadC induces an invariable effect on different genomic regions, we investigated the effect of 5azadC on non-genic repetitive sequences and some genic regions including T-DMRs in fibroblast cells.

\section{Materials and Methods}

\section{Reagents, cell culture and genome extraction}

All reagents were purchased from Wako Pure Chemicals (Osaka, Japan) unless stated otherwise.

NIH/3T3 cells were cultured in Dulbecco's modified Eagle's medium (DMEM; Invitrogen, Carlsbad, CA, USA) supplemented with $10 \%$ fetal bovine serum (JRH, Lenexa, KS, USA) and 50 unit/ $\mathrm{ml}$ penicillin / $50 \mu \mathrm{g} / \mathrm{ml}$ streptomycin (Invitrogen) at $37 \mathrm{C}$ in $5 \%$ $\mathrm{CO}_{2}$ in air. Prior to treatment with 5-aza-2'-deoxycytidine (5azadC; Sigma-Aldrich, St. Louis, MO, USA; diluted with sterile water to the concentrations required), cells were plated at $1 \times 10^{5}$ cells/150 mm dish and cultured for $24 \mathrm{~h}$. Cells were treated with 5 azadC to final concentrations ranging from 0.001 to $5 \mu \mathrm{M}$. Sterile water was substituted for $5 \mathrm{azadC}$ in the untreated control. The medium was changed every $24 \mathrm{~h}$, and cells were collected after 3 days for DNA extraction.

Wild type ES cells (J1) and mutant ES cells deficient in Dnmt1

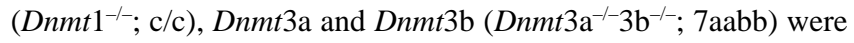
cultured on gelatin coated dishes with ES medium containing 1000 $\mathrm{U} / \mathrm{ml}$ leukemia inhibitory factor (Chemicon, Temecula, CA, USA) as previously described [24]. J1, c/c and 7aabb cells were harvested at passage numbers 32, 17 and 17 , respectively.

Cells were incubated in lysis buffer (150 mM EDTA, $10 \mathrm{mM}$ Tris-HCl, pH 8.0, and 1\% SDS) containing $10 \mathrm{mg} / \mathrm{ml}$ proteinase $\mathrm{K}$ (Merck, Darmstadt, Germany) at $55 \mathrm{C}$ for $20 \mathrm{~min}$. Following phenol/chloroform/isoamyl alcohol extraction twice, genomic DNA was precipitated with ethanol and dissolved in TE buffer (10 mM Tris-HCl, 1 mM EDTA, pH 8.0).

\section{Cell proliferation assay}

NIH/3T3 cells were seeded into 96-well plates at $1 \times 10^{3}$ cells per well, $24 \mathrm{~h}$ before 5azadC was added. Cells were treated with 5azadC at final concentrations of 0 (as the control), 0.001, 0.005, $0.01,0.05,0.1,0.5,1.0,5.0$ and $10.0 \mu \mathrm{M}$ for 3 or 4 days at $37 \mathrm{C}$ in $0.5 \% \mathrm{CO}_{2}$ in air with medium changes every $24 \mathrm{~h}$. Four hours before plate reading, $10 \mu \mathrm{l}$ of Cell Proliferation Reagent WST-1 (Roche, Penzberg, Germany) was added. The absorbance of each sample was measured against a background control using an ELISA reader at an absorption wavelength of $450 \mathrm{~nm}$.

\section{Analysis of the methylation status of repetitive sequences by Southern blotting}

Genomic DNA (5 $\mu \mathrm{g}$ ) was digested with the restriction enzyme MspI (Takara, Kyoto, Japan) or HapII (Takara) and electrophoresed on a $0.8 \%$ agarose gel. Following hydrolyzation with $0.25 \mathrm{~N}$ $\mathrm{HCl}$ and denaturation with $1.5 \mathrm{M} \mathrm{NaCl} / 0.5 \mathrm{~N} \mathrm{NaOH}$, the DNA was transferred onto a nylon membrane. The membrane was probed with pMO for endogenous C-type retrovirus (MoMuLV; Genbank accession NC_001501) and pMR150 for minor satellite repeats (X14469 and X07949). Probes were labeled with the Gene Images random prime labeling module (Amersham Pharmacia, Little Chalfont, Buckinghamshire, UK). Hybridization and detection were performed using the Gene Images CDP-star detection module (Amersham Pharmacia) according to the manufacturer's instructions.

\section{Bisulfite restriction mapping and sequencing}

Genomic DNA, digested with EcoRI, was denatured by incubating with $0.3 \mathrm{M} \mathrm{NaOH}$ at $37 \mathrm{C}$ for $15 \mathrm{~min}$. Sodium metabisulfite (pH 5.0) and hydroquinone were added to a final concentration of 2 $\mathrm{M}$ and $0.5 \mathrm{mM}$, respectively, and the mixture was incubated at $55 \mathrm{C}$ for $18 \mathrm{~h}$ in the dark. Bisulfite modified DNA was purified with the Wizard DNA Clean-Up System (Promega, Madison, WI, US), and the bisulfite reaction was terminated with $\mathrm{NaOH}$ at a final concentration of $0.3 \mathrm{M}$ at $37 \mathrm{C}$ for $15 \mathrm{~min}$. The sample was neutralized by adding $\mathrm{NH}_{4} \mathrm{OAc}, \mathrm{pH} 7.0$ (3 M, final concentration), and was precipitated with ethanol. Purified DNA was dissolved in sterile water and amplified using Immolase (Bioline, Tokyo, Japan) with the primer sets as follows: 5'-TAAGGGTAGGTATATAGGTGTGGT-3', F, and 5'-TCTACCCCСTTTAAAAATCACTTTAA3', R, for ODE; 5'-TGGGTTGAAATATTGGGTTTATTT-3', F, and 5'-CTAAAACCAAATATCCAACCATA-3', R, for OPR; 5'GGGAAGGGGATTTTGTTATTGTAGT-3', F, and 5'-CATAAACCCAACAACAAACCCATCT-3', R, for Per1; 5'-GTTAGGGTTTTTTTAG-GGTATTAGT-3', F, and 5'-CCCTAATCTACCCAACATATACAAA-3', R, for Sall3. The PCR conditions were as follows: $95 \mathrm{C}$ for $10 \mathrm{~min}$, followed by 40 cycles of denaturation at $94 \mathrm{C}$ for $30 \mathrm{sec}$, annealing at $55 \mathrm{C}$ for $30 \mathrm{sec}$ and extension at $72 \mathrm{C}$ for $1 \mathrm{~min}$, with a final extension at $72 \mathrm{C}$ for $10 \mathrm{~min}$.

Oct-4 distal enhancer, Oct-4 proximal enhancer and promoter PCR products were digested with TaqI (Takara) at 65 C, and Per1 and Sall3 PCR products were digested with HpyCH4IV (NEB, Ipswich, MA, USA) at $37 \mathrm{C}$ for $3 \mathrm{~h}$. Restricted fragments were assessed by agarose gel electrophoresis. Images were recorded and semi-quantified using the ImageJ software provided by the National Institutes of Health (http://rsbweb.nih.gov/ij/). The relative DNA methylation level of each genic region was calculated by the formula: DNA methylation status $(\%)=100 \times \mathrm{I}^{\mathrm{C}} /\left(\mathrm{I}^{\mathrm{UC}}+\mathrm{I}^{\mathrm{C}}\right)$, where $\mathrm{I}^{\mathrm{C}}$ and $\mathrm{I}^{\mathrm{UC}}$ represent the intensities of the digested and undigested bands, respectively.

For bisulfite sequencing, PCR products were cloned into pGEM T-Easy vector (Promega, Madison, WI, USA), and 10 clones were sequenced for each sample. The primer sets used were 5'TGGGCTGAAATACTGGGTTCACCC-3', F, and 5' CTGAAGCCAGGTGTCCAGCCATG-3', R, for Oct-4; 5'- GGTTGGGGAATTGGTTGTT-3', F, and 5'-CAACCTACTCCTAAATCCTCCA-3', R, for Dpep1; 5'- TAGTGAGTGGGGATGTAGTATTATGG-3', F, and 5'-AACCCCTAAACAACTTCAAAATTTT-3', R, for Clu; and 5'-GTTTAGAATATTGGTGAGTAGTGGG-3', F, and 5'-CCTTAAAATAAAAATAAACATCTTAAA-3', R, for $I g f 2 r$, with the following PCR conditions: $95 \mathrm{C}$ for $10 \mathrm{~min}$, followed by 40 cycles of denaturation at $94 \mathrm{C}$ for $30 \mathrm{sec}$, annealing at $55 \mathrm{C}$ for $30 \mathrm{sec}$ and extension at $72 \mathrm{C}$ for $1 \mathrm{~min}$, with a final extension at $72 \mathrm{C}$ for $10 \mathrm{~min}$. 


\section{RNA extraction and RT-PCR}

Total RNA was extracted with TRIzol reagent (Invitrogen) according to the manufacturer's instructions. First strand cDNA was synthesized with SuperScript ${ }^{\mathrm{TM}}$ III First-Strand Synthesis System for RT-PCR (Invitrogen), and RT-PCR was performed using Taq DNA Polymerase (Promega) with primers as follows: 5'CAGGAGTGTGTGAGGGAG-3', F, and 5'-GGTGTCACTGTCCGACTTGC-3', R, for Dnmt1; 5'-ACCCATGCCAAGACTCACCTTC-3', F, and 5'-TCCACCTTCTGAGACTCTCCAG-3', R, for Dnmt3a; 5'-TCAGACACGAAGGATGCTCC-3', F, and 5'-ACAGGGTACTCCTGCACATG-3', R, for Dnmt3b; 5'TTCTACAATGAGCTGCGTGTGG-3', F, and 5'-ATGGCTGGGGTGTTGAAGGT-3', R, for $\beta$-actin; 5'-GGCGTTCGCTTTGGAAAGGTGTTC-3', F, and 5'-CTCGAACCACATCCTTCTCT-3', R, for Oct-4; 5' - CCAGTCGAAGATGCTCAACA-3', F, and 5'- TGTGATGGGGTCAGAGTCAA-3', R, for Clu; 5'- ATGCGGTATCTGACCCTCAC-3', F, and 5'ATCTGCAAAGCGTCCTTCAT-3', R, for Dpep1 and 5'CAACGTCTGTGGAAATGTGG-3', F, and 5'- CAGCCCATAGTGGTGTTGAA-3', R, for Igf2r. The PCR conditions were as follows: $95 \mathrm{C}$ for $1 \mathrm{~min}$, followed by 30 cycles of denaturation at 94 $\mathrm{C}$ for $30 \mathrm{sec}$, annealing at $60 \mathrm{C}$ for $30 \mathrm{sec}$ and extension at $72 \mathrm{C}$ for $1 \mathrm{~min}$, with a final extension at $72 \mathrm{C}$ for $5 \mathrm{~min}$.

\section{Chromatin immunoprecipitation (ChIP) assay}

ChIP assays were performed as described previously [20] using a Chromatin Immunoprecipitation (ChIP) Assay Kit (Cat. No. 17295; Upstate Biotechnology, Lake Placid, NY, USA) with antiacetylated histone $\mathrm{H} 3$ and H4 antibodies (Cat. No. 06-599 and 06598; Upstate Biotechnology), anti-trimethylated H3K4 and H3K9 (Cat. No. ab8580 and ab8898; Abcam, Cambridge, UK) and antidimethylated H3K4, H3K9 and H3K27 (Cat. No. 07-030, 07-212 and 07-452; Upstate Biotechnology). Normal rabbit IgG (Cat. No. 12-370; Upstate Biotechnology) was used as a negative control to verify immunoprecipitation specificity. PCR was performed using primers as follows: 5'- GTGAGGTGTCCGGTGACCCAAGGCAG-3', F, and 5'- CGGCTCACCTAGGGACGGTTTCACC3', R, for Oct-4; 5'- TGCTCTGGAGACACAGGAAA-3', F, and 5'-CTGGGGAAGAAAGCCAAGAT-3', R, for Clu ChIP 1; 5'ATTGCAGTGATGCCAGATGA-3', F, and 5'- ACGCACAGCAGGAGAATCTT-3', R, for Clu ChIP 2; 5'CTCCTCTTGTGGCTCCCTAA-3', F, and 5'-GGCTCCACAGAGTGCCAAG-3', R, for Dpep1. PCR was performed under the following conditions: $95 \mathrm{C}$ for $10 \mathrm{~min}$, followed by 30 cycles of denaturation at $94 \mathrm{C}$ for $30 \mathrm{sec}$, annealing at $55 \mathrm{C}$ for $30 \mathrm{sec}$ and extension at $72 \mathrm{C}$ for $1 \mathrm{~min}$, with a final extension at $72 \mathrm{C}$ for 10 min. The amount of each PCR product on an ethidium bromidestained gel image was evaluated using the ImageJ software.

\section{Results}

\section{Demethylating effect of $5 a z a d C$ on repetitive sequences}

We examined cell survival under different concentrations of 5azadC by WST-1 assay. After $72 \mathrm{~h}$, the viable cell number was largely reduced at concentrations higher than $0.5 \mu \mathrm{M}$ and was severely affected at higher concentrations (Fig. 1A). A similar effect was observed in the 96-h culture. Only minimal effects on viability were observed in cells treated with less than $0.1 \mu \mathrm{M}$ 5azadC.

To determine the effect of 5azadC on the methylation of repetitive sequences, cells were treated with $0.001 \mu \mathrm{M}$ to $5 \mu \mathrm{M}$ 5azadC, and the methylation status of repetitive sequences was analyzed using methylation-sensitive restriction enzymes. Southern hybridization was performed using two probes of differentially localized repetitive sequences, minor satellite repeats located in the centromeric regions and endogenous C-type viruses interspersed across the mouse genome [14, 24, 29]. Minor satellite repeats were demethylated extensively starting at the $0.1 \mu \mathrm{M}$ concentration (Fig. $1 \mathrm{~B}$ ), and $1 \mu \mathrm{M}$ was sufficient to induce the maximum demethylating effect. Similarly, endogenous viruses showed aggressive loss of methylation at the $0.1 \mu \mathrm{M}$ to $5 \mu \mathrm{M}$ treatment levels, but slight demethylation could be observed at a concentration as low as 0.001 $\mu \mathrm{M}$. Thus, the repetitive sequences were strongly demethylated by 5azadC. The results confirmed a previous report that 5azadC is effective in inducing demethylation dose-dependently from $0.1 \mu \mathrm{M}$ to $5 \mu \mathrm{M}$ [30].

\section{Effect of 5azadC on genic regions}

We next examined the effect of 5azadC on T-DMRs of genic regions. Oct-4 (Pou5f1) has T-DMRs in the CpG-rich promoter/ proximal enhancer region and distal enhancer region (Fig. 1C; 20). The DNA methylation status of the T-DMRs was analyzed using bisulfite restriction mapping focusing on TaqI restriction sites. At 0.001 and $0.01 \mu \mathrm{M}$ 5azadC, the methylation levels of the investigated regions changed little compared to the untreated ones. A significant loss of methylation in both regions was observed at 0.1 $\mu \mathrm{M}$, indicating that this concentration was able to induce demethylation in both genic regions and the repetitive sequences. In the 1 and $5 \mu \mathrm{M}$ treated samples, however, both T-DMRs had nearly the same methylation levels as in the untreated control, in contrast to the extensive demethylation observed in the repetitive sequences at these concentrations.

Sall3 has a T-DMR located at an edge of a CpG island, which is methylated only in the trophoblast cell lineage [19, 21]. The TDMR is aberrantly methylated in the placental genome of cloned mice [21]. Per1, which is involved in generating circadian rhythm, has a few CpGs in the upstream promoter region. Similar to Oct-4, 0.001 and $0.01 \mu \mathrm{M}$ 5azadC had minimal effects on these loci. The methylation levels decreased significantly following $0.1 \mu \mathrm{M}$ 5azadC treatment, but were only slightly decreased at $1 \mu \mathrm{M}$, and remained unchanged at $5 \mu \mathrm{M}$.

Bisulfite sequencing was performed on several gene loci containing CpG-rich promoters, including Oct-4. Hypomethylation of the Clusterin (Clu) promoter is associated with high gene expression in the rat testis and epididymis [31]. Dpep1, a renal Dipeptidase gene, has been reported to be a tumor marker candidate in malignancies [32]. All investigated loci had hypermethylated promoter regions in NIH/3T3 cells (Fig. 2A). Bisulfite sequencing results for the Oct-4 promoter region validated the restriction mapping results showing that $0.1 \mu \mathrm{M}$ was more effective in inducing demethylation in genic regions compared with $1 \mu \mathrm{M}$. Similar dose-dependent demethylation patterns were also 
A

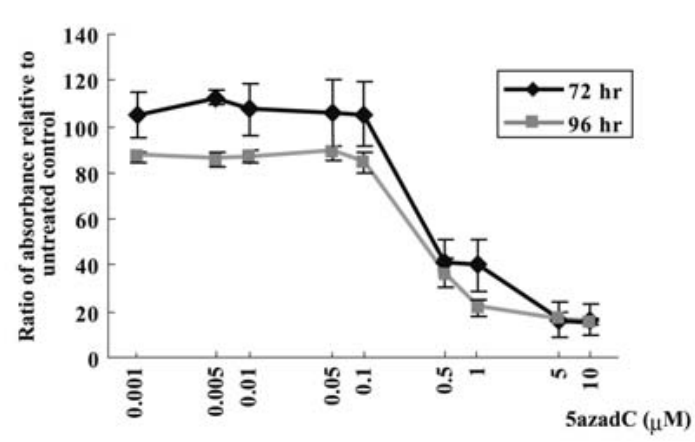

B

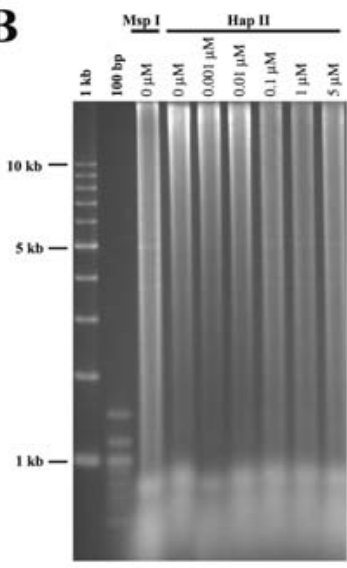

Ethidium bromide

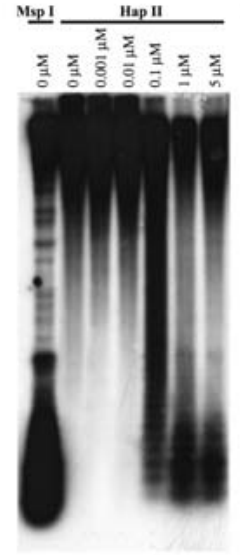

Minor satelite

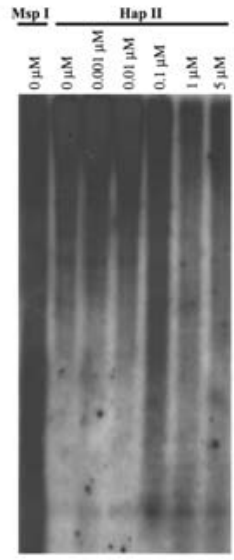

Endogenous virus
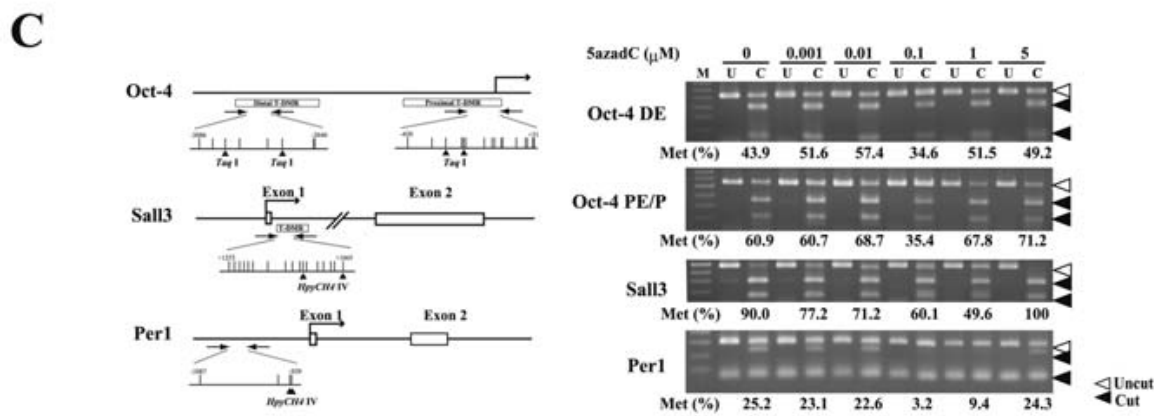

\section{Oct-4 DE}

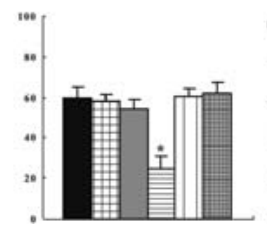

Oct-4 PE/P

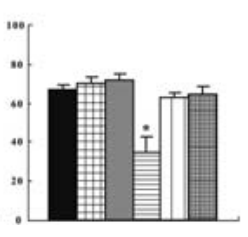

Sall3

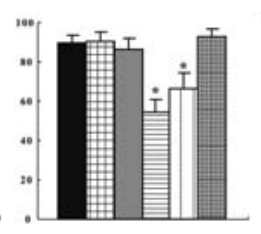

Per1

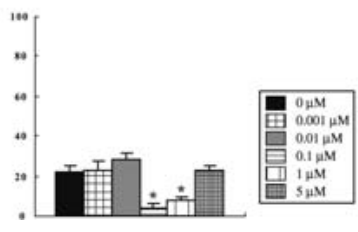

Fig. 1. Different demethylating effects of 5azadC on repetitive sequences and genic regions. A: A WST-1 cell proliferation assay was performed on cells treated with 5azadC at the indicated concentrations for 72 and $96 \mathrm{~h}$. Cell number was estimated by the absorbance, and then represented as the ratio relative to the untreated control, the absorbance of which was arbitrarily set to 100 . The values represent means \pm S.E. of 3 independent cultures. B: Analysis of the methylation status of repetitive sequences by Southern hybridization. Genomic DNA ( $5 \mu \mathrm{g}$ ), digested with HapII, was hybridized to probes for minor satellite repeats and endogenous viruses. As a control for complete digestion, DNA from the untreated control was digested with MspI. C: Methylation analysis of T-DMRs by bisulfite restriction mapping. A schematic diagram of each investigated locus is shown in the top left panel. T-DMRs are represented by bars, and CG sites are represented by vertical lines. The locations of the amplified regions relative to each respective transcription start site are as follow: Oct-4 distal enhancer (DE), -3086 to -2646 ; Oct-4 proximal enhancer/promoter (PE/P), -420 to +31 ; Sall3, +1253 to +1665; and Per1, -1087 to -929. Each locus contains 2 TaqI or HpyCH4IV restriction sites, respectively (triangles). PCR products were digested with restriction enzymes and electrophoresed on agarose gel (top right panel). The relative DNA methylation level was calculated based on the relative intensities of cut to uncut bands, indicated below each cut lane. $\mathrm{M}$, marker; $\mathrm{U}$, uncut; $\mathrm{C}$, cut with restriction enzyme. The bottom panel indicates the methylation level of each gene locus at each concentration; the values are presented as means \pm S.E. of 3 independent PCRs of 2 cultures. $* \mathrm{P}<0.05$ (Student’s $t$-test).

observed in the promoter regions of Clu and Dpep1.

We also analyzed the DMR2 region of the Igf2r imprinted gene, which is differentially methylated depending on its parental origin [33]. Due to allele-specific methylation, half of the clones were methylated in the untreated control. As observed in other genes, the DMR2 region appeared demethylated at $0.1 \mu \mathrm{M}$, but was not affected by $1 \mu \mathrm{M}$ 5azadC.

These results provide evidence that $5 \mathrm{azadC}$ has a strong demethylating effect on repetitive sequences, but its effect on genic regions is limited to a certain effective dose. The expression levels 
A

B
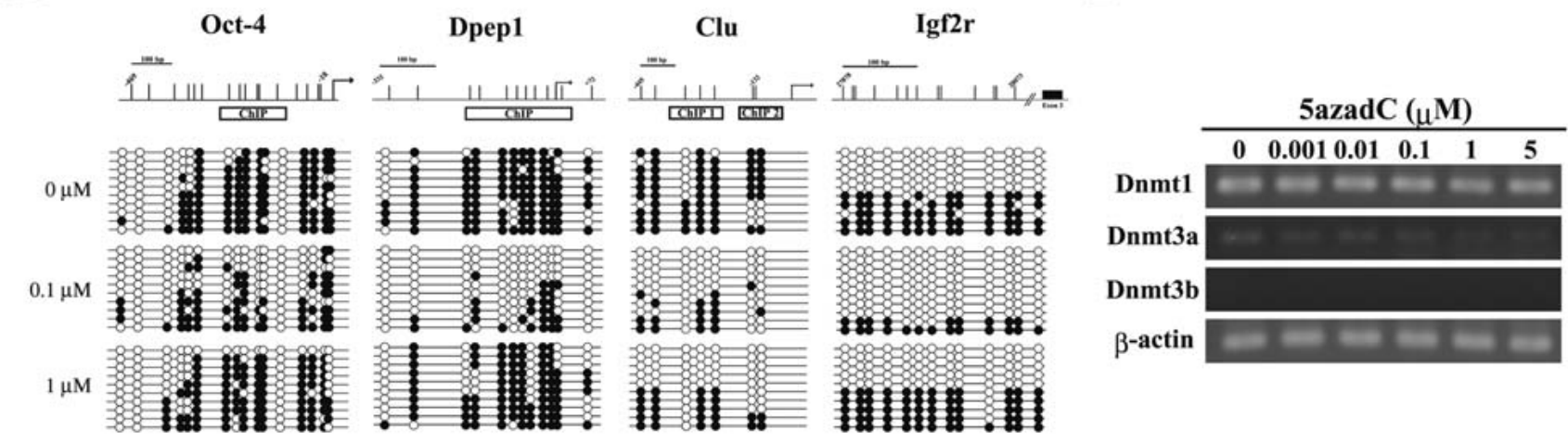

C
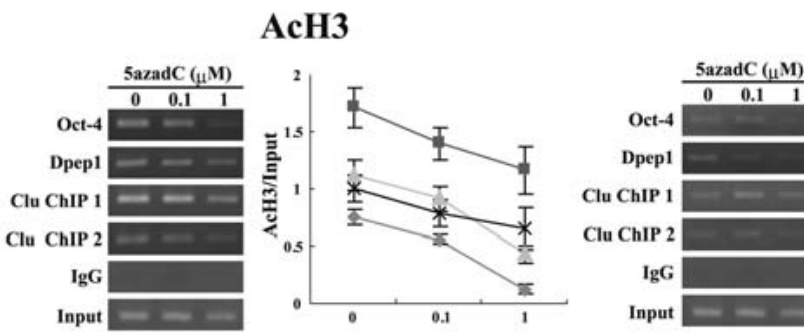

AcH4

H3K4me2
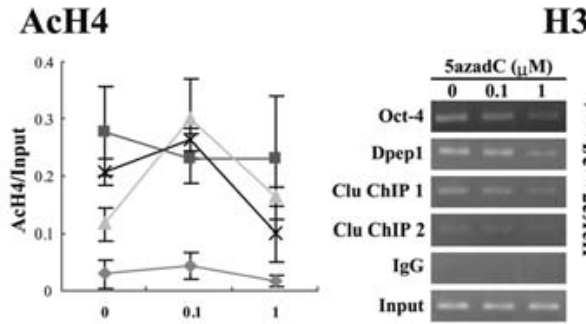

H3K27me2
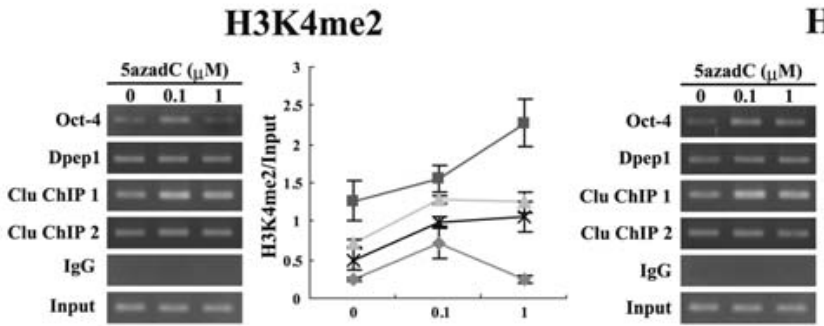

H3K4me3

\section{H3K9me2}

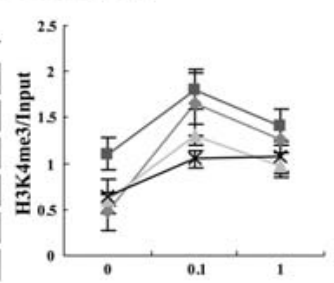

$$
\begin{aligned}
& -\because \text { Oct-4 } \\
& - \text { Dpep1 } \\
& - \text { Clu1 } \\
& - \text { - Clu } 2 \\
& \hline
\end{aligned}
$$

D
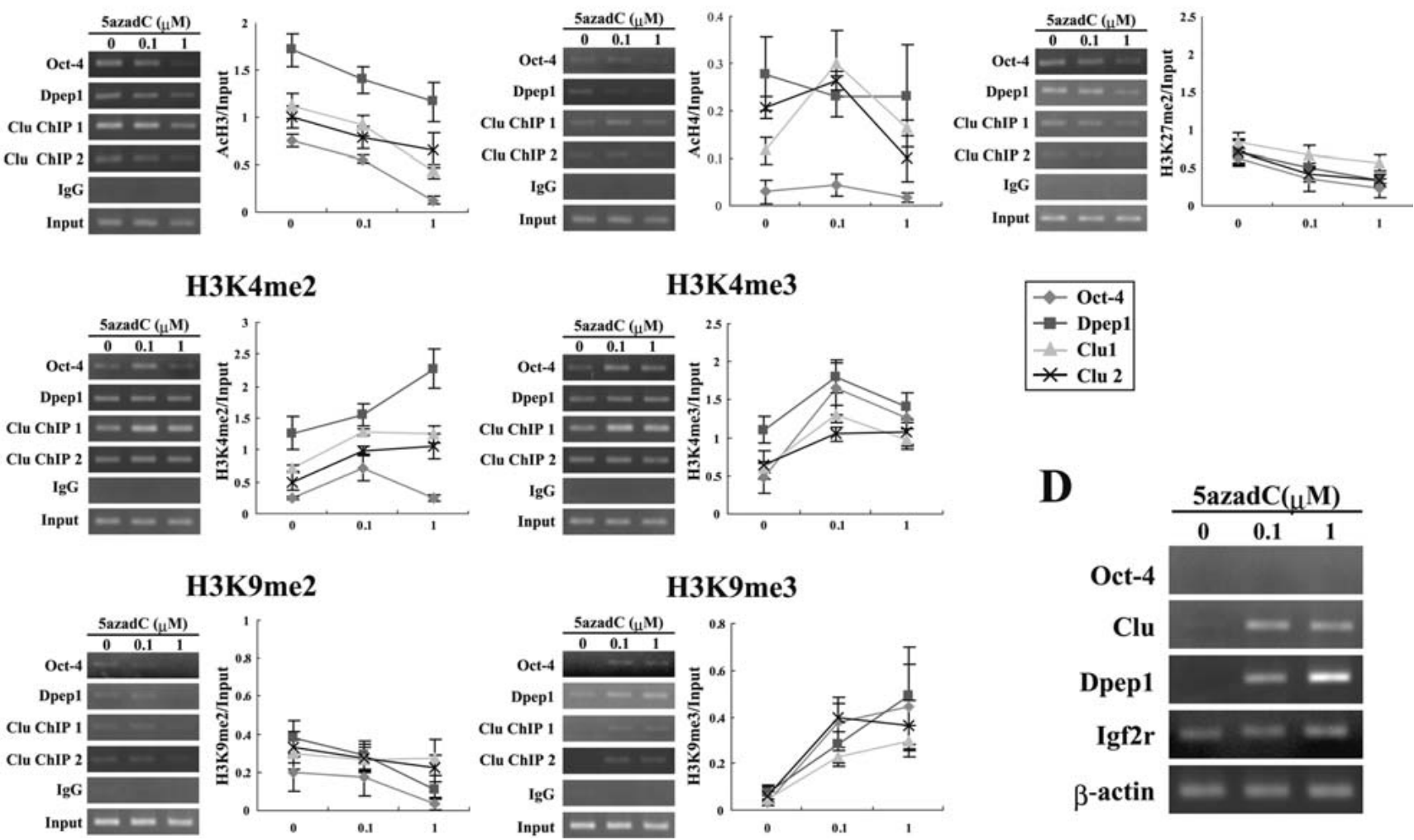

H3K9me3
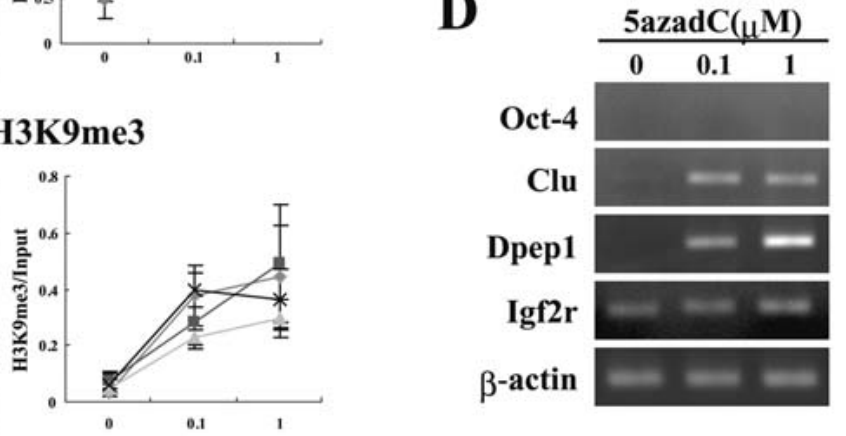

Fig. 2. Effect of 5azadC on DNA methylation, histone modification and gene expression. A: DNA methylation analysis of 4 gene loci, Oct-4, Clu, Dpep1 and Igf2r, using bisulfite sequencing. The top panel shows the location of individual CpG sites (vertical lines) in genic regions amplified by PCR. The 0, 0.1 and $1 \mu \mathrm{M}$ 5azadC-treated DNA was bisulfite converted and sequenced. The methylation status of each CpG site is represented by open (unmethylated) or closed (methylated) circles. B: Expression of Dnmt1, Dnmt3a and Dnmt3b at 0-5 $\mu \mathrm{M}$ 5azadC analyzed by RT-PCR. The expression level of $\beta$-actin was used as the internal control. C: Histone modification analysis of $0,0.1$ and $1 \mu \mathrm{M} 5 \mathrm{azadC}$-treated samples by ChIP. Analyzed regions are indicated by boxed "ChIP" in the schematic diagram in A. DNA immunoprecipitated with respective antibodies was amplified by PCR and electrophoresed (left panels). The relative intensities of PCR bands to those of the input DNA, presented as the means \pm S.E. of 3 independent PCRs of 3 cultures, are shown in the right panels. D: RT-PCR results for the expression of each gene following 5azadC treatment. 
of Dnmt1, Dnmt3a and Dnmt3b were not affected by 5 azadC at concentrations from 0.001 to $5 \mu \mathrm{M}$ (Fig. 2B), indicating that the partial retention of methylation observed at high concentrations of 5azadC was not due to increased Dnmt expression.

\section{5azadC induced a unique combination of histone tail modifications}

Since 0.1 and $1 \mu \mathrm{M}$ 5azadC showed rather unexpected, different demethylation effects on genic regions, we investigated changes in histone modifications by performing a ChIP assay with antibodies against euchromatic and heterochromatic marks. The AcH3 level in genic regions continuously declined as the concentration of 5azadC increased (Fig. 2C), which is in contrast to the condition in decondensed chromatin [26]. Such changes were not observed in $\mathrm{AcH} 4$, which was less enriched in genic regions.

Both the H3K4me2 and H3K4me3 levels increased with 5azadC treatment, in almost all investigated regions, and high levels were correlated with increased gene expression (Fig. 2D). Elevation of H3K4me2 in Dpep1 at $1 \mu \mathrm{M}$ 5azadC corresponded to a remarkable transcriptional increase, and the relatively low abundance of H3K4me2 in the Oct-4 promoter region at any level of 5azadC did not induce Oct-4 expression. H3K4me3 was more enriched by 0.1 $\mu \mathrm{M}$ than by $1 \mu \mathrm{M}$ 5azadC treatment.

Heterochromatin-associated H3K9me2 and H3K27me2 marks continuously decreased with 5azadC treatment. In contrast, elevation of H3K9me3 was observed, with higher enrichment at $1 \mu \mathrm{M}$ compared with $0.1 \mu \mathrm{M}$ 5azadC in most regions. Altogether, 5azadC treatment at different concentrations was accompanied by a distinct combination of changes in euchromatic and heterochromatic histone marks in genic regions.

\section{Increase of $\mathrm{H} 3 \mathrm{~K} 9 \mathrm{me} 3$ correlates with partially methylated} regions

Previous studies show that H3K9 methylation directs DNA methylation [34, 35]. To date, our data have shown that 5azadC induces partial demethylation, not complete demethylation, in genic regions. To determine whether increased H3K9me3 is associated with DNA methylation, we investigated enrichment of H3K9 methylation in the Dpep1 and Clu promoter regions in Dnmt-deficient cells. The promoter regions of Dpep1 and Clu were heavily methylated in wild type ES cells and were demethylated in Dnmt1 $1^{-/}$and Dnmt $3 a^{-/-} 3 b^{-/-}$(Fig. 3A). The increase of H3K9me3 in the genic regions of Dnmt knockout cells was not as obvious as those in the 5azadC-treated NIH/3T3 cells (Fig. 3B). Therefore, increased H3K9me3 correlated with partially methylated regions, such as in 5azadC-treated cells. Similar to 5azadCtreated cells, H3K9me2 decreased in Dnmt1 $1^{-/}$cells, but was increased in Dnmt $3 a^{-/-} 3 b^{-/-}$cells.

\section{Discussion}

The current results demonstrate that 5azadC has differential effects on non-genic repetitive sequence and genic regions (Fig. 4). Importantly, non-genic repetitive sequences are susceptible to 5 azadC, whereas genic regions are only demethylated by effective low doses.
A

Dpep1

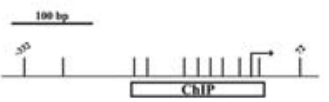

WT

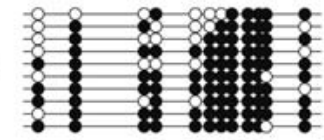

Dnmt1-/-

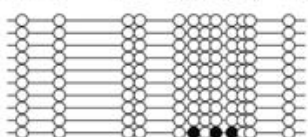

Dnmt3a
$3 \mathbf{b}^{-/-}$

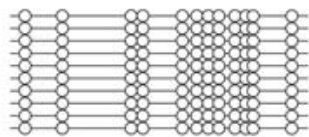

Clu
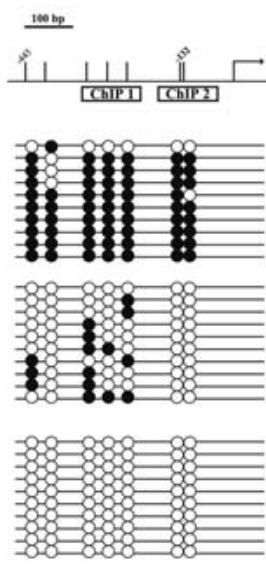

B

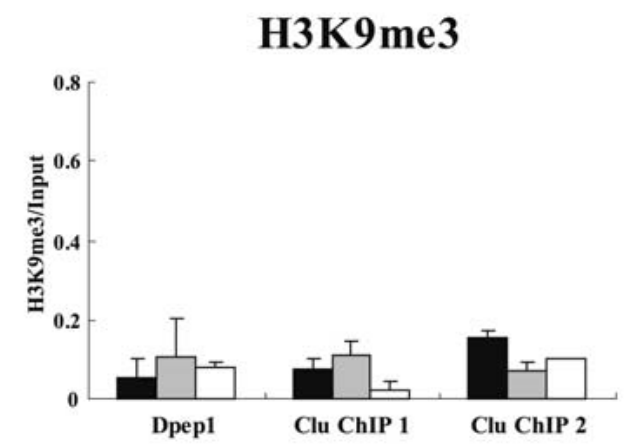

H3K9me2

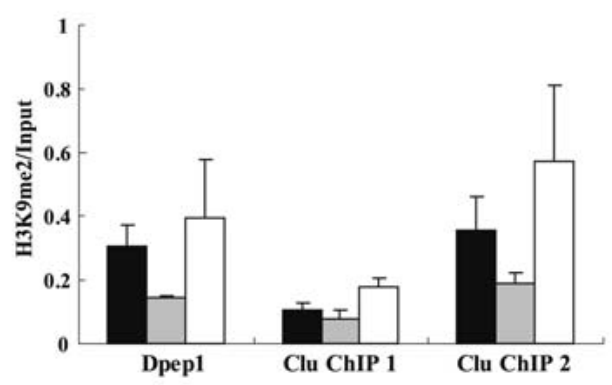

$\square$ WT $\square$ Dnmt1 $^{-/-} \square$ Dnmt3a $a^{-/-} 3 b^{-/-}$

Fig. 3. DNA methylation and H3K9 methylation status of Dpep1 and Clu in Dnmt knockout ES cells. A: DNA methylation analysis of Dpep1 and Clu by bisulfite sequencing. B: H3K9 di- and trimethylation levels in the regions shown in panel A assessed by ChIP. The bar charts show the relative intensities of PCR bands to those of the input; the values are presented as means \pm S.E. of 3 independent PCRs of 2 cultures.

Demethylation of repetitive sequences was concentrationdependent, whereas genic regions were only demethylated at effective concentrations, but not at higher concentrations. Thus, 


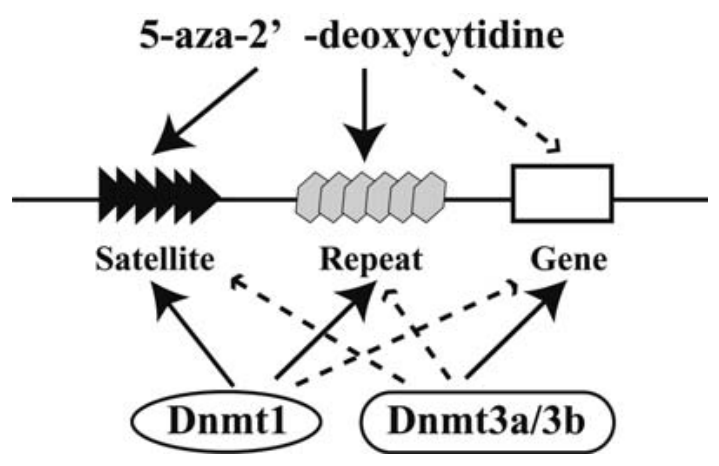

Fig. 4. Summary of the effect of 5azadC on repetitive sequences and genic regions. Repetitive sequences (black arrows) are strongly demethylated by $5 \mathrm{azadC}$, but genic regions are only demethylated at low doses (dotted arrow). The present study suggests the preference of 5azadC for Dnmt1, as Dnmt1 has a functional preference for repeats, whereas Dnmt3a and Dnmt3b functions on genic regions [24].

increasing the treatment dosage might not effectively induce demethylation in targeted genic regions, but will lead to genome-wide hypomethylation in non-cancer cells. Loss of methylation promotes additional genomic changes, including increased mutation rate and pericentromeric rearrangement $[17,36]$. Thus, before using 5azadC, precise doses should be determined to achieve localized hypomethylation, but avoid concurrent global hypomethylation.

Some reports have shown that 5azadC treatment is followed by decreased H3K9 methylation [37-39]. Our results also showed decreased H3K9me2, but increased H3K9me3 in all genic regions after 5azadC treatment. H3K9me3, but not H3K9me2, is a mark for cytosine methylation in chromatin regions in Neurospora crassa [35]. Thus, increased H3K9me3 might be associated with partial methylation in 5azadC-treated cells, indicating a functional difference between H3K9me2 and H3K9me3 in mammalian cells.

Unusual histone tail modifications were observed following 5azadC treatment, in contrast to their authentic roles in DNA methylation and gene silencing $[25,26]$. Such changes might reflect mechanisms to prevent full demethylation in genic regions. As DNA methyltransferases are associated with H3K9 methyltransferases [40, 41], accumulation of histone methyltransferases, which confers increase in H3K9me3, may also attracts Dnmts. Recruitment of MeCPs to the methylated DNA region is associated with a corepressor complex containing $\mathrm{mSin} 3$ and histone deacetylases (HDACs), causing reduction of AcH3 [42, 43]. Given that Dnmt1 has preference for repetitive sequence, whereas Dnmt3a and $3 b$ favor gene regions [24], the current study may reflect the preference of 5azadC for Dnmt1 (Fig. 4). Thus, Dnmt3 might be associated with H3K9 methyltransferases for maintaining the methylation level in genic regions due to the functional cooperation of Dnmt1 and Dnmt3 [22-24, 44, 45].

Gene activation by 5azadC seems to involve a complex mechanism of action, in addition to DNA demethylation [37, 39]. We showed that genes were upregulated at $0.1 \mu \mathrm{M}$ and that expressions were maintained or increased at $1 \mu \mathrm{M}$, despite higher methylation levels observed at $1 \mu \mathrm{M}$. Although transcriptional activation could be explained by an increase of H3K4 methylation marks [46], AcH3 concurrently decreased drastically. Interestingly, H3K4me3 abundance was lower in the $1 \mu \mathrm{M}$ treatment than in the $0.1 \mu \mathrm{M}$ treatment and was accompanied by DNA hypermethylation. A similar study on cancer genes suggested that histone modifications of demethylated genes do not fully recover to euchromatic states [47]. Interestingly, recent findings have shown that H3K9me3 is associated with active genes [48-49] and is dynamically present in active transcribed regions together with heterochromatin protein, HP1 $\gamma$ [50], suggesting the role of H3K9me3 in 5azadC-induced gene activation. Thus, gene activation by 5 azadC seems to be more complex than the authentic model of epigenetic gene activation and silencing.

Although studies have shown that the toxicity of the 5azadC treatment is not due to a demethylating effect [51], our results raise questions concerning the 5azadC toxicity mechanism. Repetitive sequences were partially demethylated at $0.1 \mu \mathrm{M}$ and were extensively demethylated at 1 and $5 \mu \mathrm{M}$. Concurrent with demethylation, cell viability was minimally affected at $0.1 \mu \mathrm{M}$, but was retarded at 1 and $5 \mu \mathrm{M}$, reflecting that the induced cytotoxicity might be an effect of global demethylation in the repetitive sequences. In contrast, genic regions were hypomethylated at 0.1 $\mu \mathrm{M}$, and were methylated at 1 and $5 \mu \mathrm{M}$ 5azadC, probably as a resistance mechanism against cell death.

This study provides an explanation of the mechanisms behind the dual modes of action of the demethylating drug 5azadC. At low concentrations, the demethylating effect is potent in both repetitive and genic regions. At high concentrations, repetitive sequences are highly demethylated, which potentially leads to toxicity. DNA methylation in genic regions is less affected, which might be due to changes in histone modification attempting to maintain the DNA methylation level. Thus, an appropriate dose of 5azadC should be wisely chosen for therapeutic use.

\section{Acknowledgments}

We appreciate Dr En Li for providing us with the ES cells and probes. This work was supported in part by the Program for Promotion of Basic Research Activities for Innovative Biosciences (PROBRAIN), Japan (to KS); Health Science Research Grant from Ministry of Health, Labor and Welfare, Japan (to KS); Program for Promotion of Fundamental in Studies in Health Sciences of the National Institute of Biomedical Innovation, Japan (to KS); and a Grant-in-Aid for Scientific Research from the Ministry of Education, Culture, Sports, Science and Technology of Japan (20062003 to ST).

\section{References}

1. Herman JG, Umar A, Polyak K, Graff JR, Ahuja N, Issa JP, Markowitz S, Willson JK, Hamilton SR, Kinzler KW, Kane MF, Kolodner RD, Vogelstein B, Kunkel TA, Baylin SB. Incidence and functional consequences of hMLH1 promoter hypermethylation in colorectal carcinoma. Proc Natl Acad Sci USA 1998; 95: 6870-6875.

2. Esteller M, Hamilton SR, Burger PC, Baylin SB, Herman JG. Inactivation of the DNA repair gene O6-methylguanine-DNA methyltransferase by promoter hypermethylation is a common event in primary human neoplasia. Cancer Res 1999; 59: 793-797. 
3. Tessema M, Langer F, Dingemann J, Ganser A, Kreipe H, Lehmann U. Aberrant methylation and impaired expression of the p15(INK4b) cell cycle regulatory gene in chronic myelomonocytic leukemia (CMML). Leukemia 2003; 17: 910-918.

4. Creusot F, Acs G, Christman JK. Inhibition of DNA methyltransferase and induction of Friend erythroleukemia cell differentiation by 5-azacytidine and 5-aza-2'-deoxycytidine. J Biol Chem 1982; 257: 2041-2048.

5. Cheng JC, Weisenberger DJ, Gonzales FA, Liang G, Xu GL, Hu YG, Marquez VE, Jones PA. Continuous zebularine treatment effectively sustains demethylation in human bladder cancer cells. Mol Cell Biol 2004; 24: 1270-1278.

6. Villar-Garea A, Fraga MF, Espada J, Esteller M. Procaine is a DNA-demethylating agent with growth-inhibitory effects in human cancer cells. Cancer Res 2003; 63: 49844989.

7. Cortez CC, Jones PA. Chromatin, cancer and drug therapies. Mutat Res 2008; 647: 4451.

8. Daskalakis M, Nguyen TT, Nguyen C, Guldberg P, Kohler G, Wijermans P, Jones PA, Lubbert M. Demethylation of a hypermethylated P15/INK4B gene in patients with myelodysplastic syndrome by 5 -Aza-2'-deoxycytidine (decitabine) treatment. Blood 2002; 100: 2957-2964

9. Zhu WG, Dai Z, Ding H, Srinivasan K, Hall J, Duan W, Villalona-Calero MA, Plass C, Otterson GA. Increased expression of unmethylated CDKN2D by 5-aza-2'-deoxycytidine in human lung cancer cells. Oncogene 2001; 20: 7787-7796.

10. Issa JP, Garcia-Manero G, Giles FJ, Mannari R, Thomas D, Faderl S, Bayar E, Lyons J, Rosenfeld CS, Cortes J, Kantarjian HM. Phase 1 study of low-dose prolonged exposure schedules of the hypomethylating agent 5-aza-2'-deoxycytidine (decitabine) in hematopoietic malignancies. Blood 2004; 103: 1635-1640.

11. Jabbour E, Issa JP, Garcia-Manero G, Kantarjian H. Evolution of decitabine development: accomplishments, ongoing investigations, and future strategies. Cancer 2008; 112: 2341-2351.

12. de Lima M, Ravandi F, Shahjahan M, Andersson B, Couriel D, Donato M, Khouri I, Gajewski J, van Besien K, Champlin R, Giralt S, Kantarjian H. Long-term follow-up of a phase I study of high-dose decitabine, busulfan, and cyclophosphamide plus allogeneic transplantation for the treatment of patients with leukemias. Cancer 2003; 97: $1242-1247$.

13. Oki Y, Aoki E, Issa JP. Decitabine--bedside to bench. Crit Rev Oncol Hematol 2007; 61: 140-152.

14. Waterston RH, Lindblad-Toh K, Birney E, et al. Initial sequencing and comparative analysis of the mouse genome. Nature 2002; 420: 520-562.

15. Yang AS, Estecio MR, Doshi K, Kondo Y, Tajara EH, Issa JP. A simple method for estimating global DNA methylation using bisulfite PCR of repetitive DNA elements. Nucleic Acids Res 2004; 32: e38.

16. Jeong KS, Lee $\mathbf{S}$. Estimating the total mouse DNA methylation according to the B1 repetitive elements. Biochem Biophys Res Commun 2005; 335: 1211-1216.

17. Ji W, Hernandez R, Zhang XY, Qu GZ, Frady A, Varela M, Ehrlich M. DNA demethylation and pericentromeric rearrangements of chromosome 1. Mutat Res 1997; 379: 33-41.

18. Weber M, Schubeler $\mathbf{D}$. Genomic patterns of DNA methylation: targets and function of an epigenetic mark. Curr Opin Cell Biol 2007; 19: 273-280.

19. Shiota K, Kogo Y, Ohgane J, Imamura T, Urano A, Nishino K, Tanaka S, Hattori N Epigenetic marks by DNA methylation specific to stem, germ and somatic cells in mice. Genes Cells 2002; 7: 961-969.

20. Hattori N, Nishino K, Ko YG, Hattori N, Ohgane J, Tanaka S, Shiota K. Epigenetic control of mouse Oct-4 gene expression in embryonic stem cells and trophoblast stem cells. J Biol Chem 2004; 279: 17063-17069.

21. Ohgane J, Wakayama T, Senda S, Yamazaki Y, Inoue K, Ogura A, Marh J, Tanaka S, Yanagimachi R, Shiota K. The Sall3 locus is an epigenetic hotspot of aberrant DNA methylation associated with placentomegaly of cloned mice. Genes Cells 2004; 9: 253260.

22. Liang G, Chan MF, Tomigahara Y, Tsai YC, Gonzales FA, Li E, Laird PW, Jones PA. Cooperativity between DNA methyltransferases in the maintenance methylation of repetitive elements. Mol Cell Biol 2002; 22: 480-491.

23. Chen T, Ueda Y, Dodge JE, Wang Z, Li E. Establishment and maintenance of genomic methylation patterns in mouse embryonic stem cells by Dnmt3a and Dnmt3b. Mol Cell Biol 2003; 23: 5594-5605

24. Hattori N, Abe T, Hattori N, Suzuki M, Matsuyama T, Yoshida S, Li E, Shiota K. Preference of DNA methyltransferases for CpG islands in mouse embryonic stem cells. Genome Res 2004; 14: 1733-1740.

25. Lachner M, Jenuwein $\mathbf{T}$. The many faces of histone lysine methylation. Curr Opin Cell Biol 2002; 14: 286-298.

26. Vermaak D, Ahmad K, Henikoff S. Maintenance of chromatin states: an open-andshut case. Curr Opin Cell Biol 2003; 15: 266-274.
27. Ikegami K, Iwatani M, Suzuki M, Tachibana M, Shinkai Y, Tanaka S, Greally JM, Yagi S, Hattori N, Shiota K. Genome-wide and locus-specific DNA hypomethylation in G9a deficient mouse embryonic stem cells. Genes Cells 2007; 1: 1-11.

28. Ikegami K, Ohgane J, Tanaka S, Yagi S, Shiota K. Interplay between DNA methylation, histone modification and chromatin remodeling in stem cells and during development. Int J Dev Biol 2009; 53: 203-214.

29. Joseph A, Mitchell AR, Miller OJ. The organization of the mouse satellite DNA at centromeres. Exp Cell Res 1989; 183: 494-500.

30. Davidson S, Crowther P, Radley J, Woodcock D. Cytotoxicity of 5-aza-2'-deoxycytidine in a mammalian cell system. Eur J Cancer 1992; 28: 362-368.

31. Rosemblit N, Chen CL. Regulators for the rat clusterin gene: DNA methylation and cis-acting regulatory elements. J Mol Endocrinol 1994; 13: 69-76.

32. McIver CM, Lloyd JM, Hewett PJ, Hardingham JE. Dipeptidase 1: a candidate tumor-specific molecular marker in colorectal carcinoma. Cancer Lett 2004; 209: 67-74.

33. Stoger R, Kubicka P, Liu CG, Kafri T, Razin A, Cedar H Barlow DP. Maternal-specific methylation of the imprinted mouse Igf2r locus identifies the expressed locus as carrying the imprinting signal. Cell 1993; 73: 61-71.

34. Jackson JP, Lindroth AM, Cao X, Jacobsen SE. Control of CpNpG DNA methylation by the KRYPTONITE histone H3 methyltransferase. Nature 2002; 416: 556-560.

35. Tamaru H, Zhang X, McMillen D, Singh PB, Nakayama J, Grewal SI, Allis CD Cheng X, Selker EU. Trimethylated lysine 9 of histone H3 is a mark for DNA methylation in Neurospora crassa. Nat Genet 2003; 34: 75-79.

36. Chen RZ, Pettersson U, Beard C, Jackson-Grusby L, Jaenisch R. DNA hypomethylation leads to elevated mutation rates. Nature 1998; 395: 89-93.

37. Wozniak RJ, Klimecki WT, Lau SS, Feinstein Y, Futscher BW. 5-Aza-2'-deoxycytidine-mediated reductions in G9A histone methyltransferase and histone H3 K9 dimethylation levels are linked to tumor suppressor gene reactivation. Oncogene 2007; 26: 77-90.

38. Nguyen CT, Weisenberger DJ, Velicescu M, Gonzales FA, Lin JC, Liang G, Jones PA. Histone H3-lysine 9 methylation is associated with aberrant gene silencing in cancer cells and is rapidly reversed by 5-aza-2'-deoxycytidine. Cancer Res 2002; 62: 64566461.

39. Fahrner JA, Eguchi S, Herman JG, Baylin SB. Dependence of histone modification and gene expression on DNA hypermethylation in cancer. Cancer Res 2002; 62: 72137218 .

40. Fuks F, Hurd PJ, Deplus R, Kouzarides T. The DNA methyltransferases associate with HP1 and the SUV39H1 histone methyltransferase. Nucleic Acids Res 2003; 31: 2305-2312.

41. Li H, Rauch T, Chen ZX, Szabo PE, Riggs AD, Pfeifer GP. The histone methyltransferase SETDB1 and the DNA methyltransferase DNMT3A interact directly and localize to promoters silenced in cancer cells. J Biol Chem 2006; 281: 19489-19500.

42. Jones PL, Veenstra GJ, Wade PA, Vermaak D, Kass SU, Landsberger N, Strouboulis J, Wolffe AP. Methylated DNA and MeCP2 recruit histone deacetylase to repress transcription. Nat Genet 1998; 19: 187-191.

43. Nan X, Ng HH, Johnson CA, Laherty CD, Turner BM, Eisenman RN, Bird A. Transcriptional repression by the methyl-CpG-binding protein $\mathrm{MeCP} 2$ involves a histone deacetylase complex. Nature 1998; 393: 386-389.

44. Rhee I, Jair KW, Yen RW, Lengauer C, Herman JG., Kinzler KW, Vogelstein B, Baylin SB, Schuebel KE. CpG methylation is maintained in human cancer cells lacking DNMT1. Nature 2000; 404: 1003-1007.

45. Rhee I, Bachman KE, Park BH, Jair KW, Yen RW, Schuebel KE, Cui H, Feinberg AP Lengauer C, Kinzler KW, Baylin SB, Vogelstein B. DNMT1 and DNMT3b cooperate to silence genes in human cancer cells. Nature 2002; 416: 552-556.

46. Santos-Rosa H, Schneider R, Bannister AJ, Sherriff J, Bernstein BE, Emre NC Schreiber SL, Mellor J, Kouzarides T. Active genes are tri-methylated at K4 of histone H3. Nature 2002; 419: 407-411.

47. McGarvey KM, Fahrner JA, Greene E, Martens J, Jenuwein T, Baylin SB. Silenced tumor suppressor genes reactivated by DNA demethylation do not return to a fully euchromatic chromatin state. Cancer Res 2006; 66: 3541-3549.

48. Brinkman AB, Roelofsen T, Pennings S, Martens J, Jenuwein T, Stunnenberg HG. Histone modification patterns associated with the human $\mathrm{X}$ chromosome. EMBO Rep 2006; 7: 628-634.

49. Kim A, Kiefer C, Dean A. Distinctive signatures of histone methylation in transcribed coding and noncoding human $\beta$-globin sequences. Mol Cell Biol 2007; 27: 1271-1279.

50. Vakoc C, Mandat S, Olenchock B, Blobel GA. Histone H3 lysine 9 methylation and HP1 $\gamma$ are associated with transcription elongation through mammalian chromatin. Mol Cell 2005; 19: 381-391.

51. Juttermann R, Li E, Jaenisch R. Toxicity of 5-aza-2'-deoxycytidine to mammalian cells is mediated primarily by covalent trapping of DNA methyltransferase rather than DNA demethylation. Proc Natl Acad Sci USA 1994; 91: 11797-11801. 